\title{
HARMONIZING EVIDENCE BASED INFECTION PREVENTION IN EUROPE
}

\author{
J ohannes J . de Soet ${ }^{1}$ \\ ${ }^{1}$ ORAL MICROBIOLOGIST AND SPECIALIST IN HYGIENE AND INFECTION PREVENTION. \\ ACADEMIC CENTRE FOR DENTISTRY AMSTERDAM (ACTA). \\ DEPARTMENT OF PREVENTIVE DENTISTRY, AMSTERDAM, THE NETHERLANDS
}

Infection prevention has been an issue that is getting more and more attention over the last decades, possibly because of the fact that healthcare associated infection (HAI) have great impact on the patients and the healthcare workers involved. For the U.S. it is estimated that 1.7 million patients suffer from an HAI each year and from these, about 99,000 patients will die because of that infection ${ }^{1}$. In the Netherlands, about 27,000 HAI where seen in 2007-2008 and it is estimated that 1500 of these patients did not survive this infection ${ }^{2}$. Because HAIs are diseases that can be mostly prevented by taking appropriate (hygiene) measures, studying these infections in more detail is important.

The here above mentioned cases are situations that usually do not occur in the dental clinics. Most deaths due to an HAI are found in Intensive Care Units. There, patients usually have a higher risk due to their own health status and due to the prolonged exposure time in the clinic to become infected with pathogens. When a patient visits a dental clinic, the patient usually is healthy and only for a short time in contact with possible pathogens that can interfere with his health. But more things have to be taken into consideration. A good example of an HAI in dentistry is the cross contamination of Legionella pneumophila from dental water supplies. Antibody response in dental workers

Address for correspondence:

Dr. J. J. de Soet

Department of Preventive Dentistry

Academic Centre for Dentistry Amsterdam (ACTA)

A msterdam, The $\mathrm{N}$ etherlands

Phone: +31205980869

Email: j.d.soet@acta.nl show that L. pneumophila is a pathogen that is ubiquitously prevalent in dental clinics ${ }^{3-5}$. A well documented case in Italy revealed that patients can actually be infected by L. pneumophila during a dental treatment and even may die from that infection ${ }^{6}$. It is assumed that in this particular dental practice at least 500 persons have been treated during the same period that the infection occurred. Only one patient was infected, which indicates that the risk for an infection by L. pneumophila in a contaminated dental clinic is only $0.5 \%$. M oreover, it may be anticipated that also the susceptibility for such an infection plays a role. This can be concluded from a South A frican study, where in a $L$. pneumophila positive dental clinic no patients and dentists where affected, but the receptionist suffered from legionnaires' disease ${ }^{7}$. Such studies indicate that cross infection within dental clinics occurs and that the susceptibility of the receiving subject for this particular infection determines whether a true infection occurs.

In dentistry patients tend to keep their own teeth longer and these patients need dental treatment until an older age. Also performing more difficult dental treatments, like endodontic treatments and placing implants, will increase the time spend for a dental treatment. This means that with increasing number of treatments, and consequently more exposure time in

(C) 2013 Faculty of Medicine in Niš. Clinic of Dentistry in Niš. All rights reserved / (C) 2013 Medicinski fakultet Niš. Klinika za stomatologiju Niš. Sva prava zadržana 
the clinic, the risk for an HAI will increase the coming years. Moreover, with the increasing age of our patients and the appearance of more and more community acquired multi-resistant bacteria, such as CA-MRSA, the susceptibility of our patient population may change making them more vulnerable for HAI ${ }^{8}$. Consequently, dental clinics should focus more on the prevention of heal thcare associated infections because the risk of patients and staff for getting an HAI during dental treatment is increasing.

With the opening of national borders within the European Union, dentists can study and work everywhere within the EU, but the level of education and the knowledge and regulations in dental infection prevention differs greatly in these countries.

In a study on 24 dental schools in Europe performed by ACTA it was found that most countries do have some regulations on infection prevention, but there still are great differences. Items related to hand hygiene are commonly integrated in dentistry and in several dental teaching programs. Also the scientific backgrounds on hand hygiene are known to persons involved in infection prevention. Differences between countries are mostly in the field of regulations such as: who is responsible for reporting problems, how to show that a dental clinic is working according to the regulations and what will happen when a clinic is not working according to the protocols. Large differences have been found in guidelines on multi resistant microorganisms, such as MRSA. In several countries, including the Netherlands, no guidelines for dental clinics are available when a MRSA patient is treated in the dental clinic. This may be caused by a low incidence of MRSA in the $N$ etherlands, but the numbers of CA-M RSA is increasing and we should react pro-actively on that knowledge ${ }^{9}$. Also guidelines for immunization differ between countries. In several, but not all investigated countries, hepatitis B vaccinations are obligatory for working within a dental clinic. The level of vaccination in dental care workers, however, is far from $100 \%$ as would be expected from the regulations ${ }^{10}$. M oreover, other vaccination regimes differ strongly between countries. Vaccination against influenza for dental care workers, for example, is highly recommended by several scientists from the USA ${ }^{11}$. The recommendation for health care workers in European countries is clear: for an optimal protection of your patients against flu, you have to maintain strict hygiene rules but vaccination against influenza gives a better protection ${ }^{12}$. The level of vaccination in dentistry, however, is reported to be low 13,14 .

Since vaccination is the best preventive measure for several infectious diseases, this is a good example of the necessity to approach harmonization of guidelines in infections prevention. But also on other topics within infection prevention, harmonization of guidelines and protocols within the European community needs attention.

More important is the question whether national guidelines are the best way to take care that infection prevention is optimally included in dental care ${ }^{15}$. It seems that scientific knowledge alone does not provide sufficient guarantees that infection prevention is performed in a safe manner. As we know, guidelines alone without a proper scientific foundation are not sufficient either and therefore the future of infection prevention lies in harmonizing the European guidelines on the basis of scientific knowledge.

That means that we need more studies on HAIs in the dental setting. The last decades, more studies are appearing, especially from South European countries. This issue of Acta Stomatologica Naissi is a good example of what needs to be done. Also review papers such as that from Laheij et al. may help dental schools and national boards to develop evidence based guidelines on infection prevention 16 . The need for original studies that report on the risk of transmission of pathogens in the dental clinic and resulting HAIs in patients or dental staff, however, remains high and should be stimulated. Moreover, guidelines on infection prevention in dentistry should be science based and therefore not only applicable in one country: microbiological mechanisms being the basis of HAIs do not recognize the national borders. For that reason microbiologists and specialists in hygiene en infection prevention should collaborate more often and share their results to guarantee a better prevention of dentistry associated infections. 


\section{LITERATURA / REFERENCES}

1. K levens R M , Edwards JR, Richards CL, et al. Estimating health care-associated infections and deaths in U.S. hospitals, 2002. Public Health Rep 2007;122(2):1606.

2. Van der Kooi TI, Mannien J, Wille JC, van Benthem BH. Prevalence of nosocomial infections in The Netherlands, 2007-2008: results of the first four national studies. J Hosp Infect 2010;75(3):168-72.

3. Fotos PG, Westfall HN, Snyder IS, Miller RW, Mutchler BM. Prevalence of Legionella-specific IgG and IgM antibody in a dental clinic population. J Dent Res 1985;64(12):1382-5.

4. Pankhurst CL, Coulter W, Philpott-Howard JJ, Harrison T, Warburton F, Platt S, et al. Prevalence of legionella waterline contamination and Legionella pneumophila antibodies in general dental practitioners in London and rural Northern Ireland. Br Dent J 2003;195(10):591-4; discussion 81 .

5. Borella P, Bargellini A, Marchesi I, et al. Prevalence of anti-legionella antibodies among Italian hospital workers. J Hosp Infect 2008;69(2):148:55.

6. Ricci ML, Fontana S, Pinci F, et al. Pneumonia associated with a dental unit waterline. Lancet 2012;379(9816):684.

7. Chikte UM, Khondowe O, Gildenhuys I. A case study of a dental receptionist diagnosed with Legionnaires' disease. SADJ 2011;66(6):284-7.

8. Petti S, Polimeni A. Methicillin-resistant Staphylococcus aureus infection transmission in dental health care settings: myths and facts. Am J Infect Control 2012;40(3):287-8.
9. Diederen BM, Kluytmans JA. The emergence of infections with community-associated methicillin resistant Staphylococcus aureus. J Infect 2006;52(3):157-68.

10. McCarthy GM, Koval JJ, MacDonald JK, John MA. The role of age- and population-based differences in the attitudes, knowledge and infection control practices of Canadian dentists. Community Dent Oral Epidemiol 1999;27(4):298-304.

11. Kohn W G. Emerging and re-emerging infectious diseases: be prepared. J Am Dent Assoc 2010;141(1):103.

12. Maltezou HC, Wicker S, Borg M, et al. Vaccination policies for health-care workers in acute health-care facilities in Europe. Vaccine 2011;29(51):9557-62.

13. Wicker S, Rabenau HF, Betz W, Lauer HC. Attitudes of dental healthcare workers towards the influenza vaccination. Int J Hyg Environ Health 2012;215(4):4826.

14. Petti S, Messano GA, Polimeni A. Dentists' awareness toward vaccine preventable diseases. Vaccine 2011;29(45):8108-12.

15. Hubner NO, Handrup S, Meyer G, Kramer A. Impact of the „Guidelines for infection prevention in dentistry" (2006) by the Commission of Hospital Hygiene and Infection Prevention at the Robert Koch-Institute (KRIN$\mathrm{KO}$ ) on hygiene management in dental practices - analysis of a survey from 2009. GMS Krankenhhyg Interdiszip 2012;7(1):Doc14.

16. Laheij AM, Kistler JO, Belibasakis GN, Valimaa $\mathrm{H}$, de Soet JJ. Healthcare-associated viral and bacterial infections in dentistry. J Oral Microbiol 2012;4. 